\title{
Improving Student's Curiosity by ICT-Assisted Guided Inquiry Models
}

\author{
Irdalisa $^{1,}$ Mega Elvianasti ${ }^{\text {, }}$ Maesaroh 3, Husnin Nahry Yarza 4, Tuti Marjan \\ Fuadi 5 \\ DOI: $10.35445 /$ alishlah.v13i1.402
}

\section{Info Artikel}

Keywords:

Curiosity

Guided Inquiry

ICT

\section{Abstract}

The purpose of this research is that students' curiosity can be increased by using guided inquiry models assisted by ICT. In learning science, one of the things that must be improved is curiosity. Curiosity is a person's desire for information and knowledge, as well as the sensation of new experiences to be able to motivate behavior in finding out the true truth. The curiosity measured in this study, such as the desire of students to explore for new information, the desire to find a new concept or theory by applying the knowledge they have, and someone's desire to find out if there is a conflict between what is believe inversely proportional with what is reality. This study used a one group pretest posttest design and used a quantitative approach. The sample in this study was 63 fifth semester students of biology education at the University of Muhammadiyah Prof. Dr. Hamka Jakarta, Indonesia. The sample was taken by using purposive sampling technique. The research instrument used a questionnaire. Data analysis using descriptive quantitative. Based on the research results, it can be concluded that the application of the ICT-assisted guided inquiry model is more effective in increasing student curiosity. The application of technology-based inquiry is important in improving student Curiosity to make science learning more meaningful, effective, and efficient.
Kata kunci: Curiosity Inkuiri Terbimbing ICT

\begin{abstract}
Abstrak
Tujuan penelitian ini adalah rasa ingin tahu mahasiswa dapat ditingkatkan dengan model inkuiri terbimbing berbantuan ICT. Dalam pembelajaran sains sikap ilmiah yang harus ditingkatkan salah satunya adalah rasa ingin tahu. Rasa ingin tahu adalah keinginan seseorang untuk mendapatkan informasi dan ilmu (pengetahuan) baru, serta sensasi pengalaman baru untuk dapat memotivasi perilaku dalam mencari tahu suatu kebenaran yang sesungguhnya. Rasa ingin tahu yang diukur dalam penelitian ini diantaranya keinginan mahasiswa dalam melakukan eksplorasi untuk mencari informasi baru, timbulnya keinginan dalam menemukan suatu konsep atau teori baru dengan menerapkan pengetahuan yang dimilikinya, serta keinginan seseorang untuk mencari tahu disaat adanya pertentangan antara yang diyakini atau diketahui. Penelitian ini
\end{abstract}

\footnotetext{
${ }^{1}$ Universitas Muhammadiyah Prof. Dr. Hamka, Jakarta, Indonesia Email: irdalisa@uhamka.ac.id

2 Universitas Muhammadiyah Prof. Dr. Hamka, Jakarta, Indonesia

Email: megaelvianasti@uhamka.ac.id

3 Universitas Muhammadiyah Prof. Dr. Hamka, Jakarta, Indonesia

Email: maesyaroh@uhamka.ac.id

${ }^{4}$ Universitas Muhammadiyah Prof. Dr. Hamka, Jakarta, Indonesia

Email: husnin.yarza@uhamka.ac.id

5 Universitas Abdulyatama, Banda Aceh, Indonesia

Email: tuti_biologi@abdulyatama.ac.id

Vol.13 (1) June, 2021

Received: February 20, 2021; Received in revised form: March 13, 2021; Accepted: March 16, 2021; Available online: April 10, 2021

This is an open access article under a Creative Commons Attribution-NonCommercial-ShareAlike 4.o International License
} 
menggunakan one group pretest posttest design dan menggunakan pendekatan kuantitatif. Sampel dalam penelitian ini 63 mahasiswa semester lima pendidikan biologi di Universitas Muhammadiyah Prof Dr. Hamka Jakarta, Indonesia. Sampel diambil dengan teknik purposive sampling. Instrumen penelitian menggunakan angket. Analisis data menggunakan deskriptif kuantitatif. Berdasarkan hasil penelitian, dapat disimpulkan bahwa penerapan model inkuiri terbimbing berbantuan ICT lebih efektif dalam meningkatkan rasa ingin tahu mahasiswa. Penerapan inkuiri berbasis teknologi penting diterapkan dalam peningkatan Curiosity mahasiswa untuk membuat pembelajaran sains lebih bermakna, efektif, dan efisien.

\section{PENDAHULUAN}

Fenomena pandemi corona (Covid 19) saat ini mengharuskan proses pembelajaran berlangsung dengan sistem daring (pembelajaran jarak jauh), sehingga secara tidak langsung berdampak pula terhadap psikologi mahasiswa. Mahasiswa dituntut untuk memiliki tingkat kemandirian dan pengorganisasisan diri yang tinggi (Raharja, Wibhawa, \& Lukas, 2018). Pengaruh perubahan pembelajaran yang awalnya dapat dengan mudah berinteraksi langsung dengan dosen maupun antar mahasiswa, sekarang dibatasi dengan pembelajaran yang hanya dilakukan di rumah saja, sehingga membuat mahasiswa menjadi jenuh dan bosan, serta membuat kurangnya motivasi mahasiswa untuk mencari tahu tentang hal baru dalam kegiatan belajar.

Revolusi industri 4.0 dan pandemi corona yang menimpa Indonesia menuntut perubahan dan peningkatan dalam penguasaan teknologi di segala bidang khususnya dunia Pendidikan. Orientasi dan literasi baru harus dapat dipersiapkan oleh Lembaga Pendidikan. Pengandalan kemampuan membaca, menulis, dan matematikan dalam literasi lama harus semakin diperkuat dengan mempersiapkan literasi baru yang terdiri dari kemampuan dalam meliterasi data, ilmu teknologi, dan SDM yang handal (Rahmadi, 2015).

Pemanfaatan teknologi dalam proses pembelajaran telah menjadi perhatian utama seluruh komponen pendidikan karena dianggap sebagai faktor penting untuk meningkatkan mutu pendidikan (Jimayonis, A 2010). Tujuan adanya kemampuan teknologi dalam dunia pendidikan adalah untuk dapat meningkatkan pemahaman literasi dari sebuah teknologi di kalangan siswa, peningkatan pembelajaran lebih berkualitas, dan mendorong kegiatan dalam memecahkan masalah, dan rasa ingin tahu siswa (Meenakshi. 2013).

Rasa ingin tahu dalam pembelajaran sains yaitu dengan mewajibkan adanya sikap ilmiah (Anwar, 2009). Dalam proses pembelajaran sangatlah penting adanya rasa ingin tahu (Ardiyanto, 2013) kemampuan adanya rasa ingin tahu dapat membentuk siswa lebih menggunakan pikirannya dan aktif dalam mengamati sesuatu hal sehingga tercapainya kepuasan dalam diri siswa, untuk menghilangkan rasa bosan saat mengembangkan ilmu yang dimilikinya terhadap pelajaran atau konten yang diajarkan di sekolah, siswa termotivasi untuk aktif mempelajari lebih dalam sesuatu hal yang tidak diketahuinya.(Puspitasari, Santoso \& Muchsini, 2015).

Rasa ingin tahu merupakan suatu hal yang sangat mendasar dalam proses pembelajaran sains (Raida \& Jamaludin, 2020). Rasa ingin tahu menjadi pondasi dasar pada tiga tingkatan berpikir siswa (Binson, 2009), Dalam proses belajar, rasa ingin tahu siswa dieksplorasi pengalamannya dengan meningkatkan kemampuan baca, kemampuan mendengar, berpikir, dan berkomunikasi dengan baik. Rasa ingin tahu yang ada di dalam siswa mendorong sikap input read dan listen well yaitu dimana siswa akan mencari tahu sesuatu dengan cara membaca atau mendngar informasi penting agar rasa ingin tahunya terpecahkan. Hal ini sejalan dengan (Megawati, Wiarta \& Manuaba, 2015) kegiatan input read dan listen well dalam rasa ingin tahu yaitu mendorong siswa untuk memperoleh informasi sebanyak-banyaknya. (Irdalisa, Paidi \& Djukri, 2020) menyatakan pemahaman siswa terhadap bacaan yang dibacanya meningkatkan rasa ingin tahu, sehingga hal ini menunjukkan suatu hal yang positif. Binson (2009), menyatakan bahwa dasar untuk berpikir siswa dengan melakukan kegiatan input read dan listen well. proses berpikir siswa/process think well 
akan semakin baik saat informasi yang dimasukkan akurat. Untuk Process think well produk pemikiran yang dihasilkan akan membantu siswa dalam tahap berkomunikasi output communicate well. Dasar dari kegiatan input read dan listen well, process think well, dan output communicate well yang didasari dengan adanya rasa ingin tahu dapat disamakan dengan sintak yang ada pada pembelajaran berbasis pendekatan saintifik, dimana langkah tersebut menuntut adanya kegiatan mengamati, menalar, menanya, mencoba, dan mengomunikasikan.

Rasa ingin tahu mahasiswa dalam proses pembelajaran termasuk dalam kategori sangat rendah, hal ini didukung dengan uji pendahuluan penelitian terdahulu oleh Mardhiyana (2017) menyatakan bahwa perlu adanya peningkatan rasa ingin tahu mahasiswa karena dari penelitian diperoleh hasil rasa ingin tahu masih dalam kategori rendah. Penelitian lainnya yaitu (Insani, 2018) menyatakan rasa ingin tahu pada siswa kelas $\mathrm{X}$ harus lebih ditingkatkan, karena rasa ingin tahu siswa terhadap pelajaran matematika masih dalam kategori sedang.

Kurangnya rasa ingin tahu dalam diri mahasiswa dapat diatasi dengan cara dosen sebagai pengajar dan fasilitator harus lebih menyesuaikan antara model pembelajaran dengan karakteristik matakuliah yang akan diajarkan nantinya. Teori pembelajaran yang dilandasi pondasi yang kuat harus dimiliki dalam proses pengembangan model pembelajaran.

Pembelajaran daring (online) menuntut kegiatan praktikum harus terus dilakukan, salah satunya dengan cara menggunakan laboratorium virtual (Lab Virtual). Mahasiswa harus mengambil bagian dalam kegiatan perencanaan penyelidikan agar dapat memudahkan mereka dalam meningkatkan keterampilan dan penguasaan teknik laboratorium. Pelaksanaan kegiatan laboratorium dengan melibatkan langsung mahasiswa dapat meningkatkan kemampuan keterampilan proses sains, pengayaan konsep dan rasa ingin tahu mahasiswa.

Laboratorium sains di perguruan tinggi banyak menerapkan pembelajaran inkuiri terbimbing karena terbukti dapat meningkatkan proses belajar siswa (Gormally et al., 2009). Pembelajaran dengan mengunakan model inkuiri terbimbing memotivasi siswa dalam menyelesaikan permasalahan, mengidentifikasi permasalahan, mengembangkan intelektual dan merangsang rasa ingin tahu. Namun jika dikaitkan dengan peningkatan kemampuan teknologi di masyarakat penerapan model inkuiri terbimbing saja masih kurang maksimal, diperlukan perpaduan antara model inkuiri terbimbing dengan pembelajaran berbasis internet atau teknologi informasi, hal ini dikarenakan ICT dapat menjadi fasilitator inovasi pada sumber belajar, media pembelajaran. Bantuan media internet juga memudahkan pembelajaran jarak jauh dengan menghubungkan antara mahasiswa dengan dosennya.

Model inkuiri berbantuan ICT dalam penelitian ini dapat memudahkan dalam menghubungkan mahasiswa dengan dosennya untuk meningkatkan rasa ingin tahu (Curiosity) saat melakukan praktikum di laboratorium maupun secara laboratorium virtual. Hal ini sejalan dengan (Irdalisa, 2019) inkuiri terbimbing berbantuan ICT merupakan kegiatan mahasiswa menginvestigasi dan menyelesaikan permasalahan dengan pemanfaatan teknologi informasi (media internet) dalam memfasilitasi pengayaan referensi dalam sumber belajar, pendesainan media pembelajaran dan membantu proses belajar jarak jauh.

Berdasarkan uraian di atas, rasa ingin tahu menjadi suatu hal penting dalam proses belajar sains yang harus dikembangkan dalam diri mahasiswa. Dengan peningkatan rasa ingin tahu dapat menambah keinginan mahasiswa dalam mencari informasi baru, melakukan eksplorasi, memperoleh konsep baru, dan mencari tahu penyebab disaat terjadinya pertentangan antara suatu hal yang diketahui dengan diyakininya. Melalui model inkuiri terbimbing berbantuan ICT diharapkan mahasiswa dapat meningkatkan kemampuan rasa ingin tahu.

\section{METODE}

Penelitian ini menggunakan desain one group pre-test post-test dengan pendekatan kuantitatif. Populasi dalam penelitian ini adalah mahasiswa jurusan Pendidikan Biologi Universitas Muhammadiyah Prof. Dr. Hamka Jakarta, Indonesia. Penelitian ini dilakukan selama tiga bulan, 
mulai dari September hingga November 2020. Implementasi model inkuiri dilakukan berdasarkan tahapan prosedurnya. Pelaksanaan di kelas diadakan pertemuan mingguan selama 120 menit untuk setiap pertemuan. Langkah-langkah inkuiri terbimbing berbantuan ICT yang digunakan pada penelitian ini yaitu penjelasan prosedur pembelajaran, penyajian masalah pengumpulan data, pengujian hipotesis dan memformulasikan penjelasan. Ditampilkan pada tabel 1 berikut.

Tabel 1. Tahapan Pembelajaran Inkuiri Terbimbing Berbantuan ICT

Tahapan

Menjelaskan tahapan pembelajaran
Aktivitas Dosen dan Mahasiswa

Dosen menjelaskan tujuan dan
langkah-langkah
menggunakan bantuan Powelajaran
dan video pembelajaran dengan
bantuan Aplikasi Zoom.

Mahasiswa menyimak penjelasan dosen tentang tahapan prosedur pembelajaran

Dosen menyajikan masalah dan dinyatakan di dalam bentuk pertanyaan

Mahasiswa mengamati dan mencari permasalahan-permasalahan yang ada di lingkungan sekitar untuk dijadikan bahan diskusi dan mencari penyelesaian bersama anggota kelompok

Data Collection (pengumpulan data) dan pengujian hipotesis

Dosen memberikan bimbingan kepada

mahasiswa dalam kegiatan pengumpulan data dan pengujian hipotesis. Dan penjelasan penggunaan Laboratorium Virtual

Mahasiswa diarahkan untuk mengidentifikasi informasidan menambahkan referensi dari berbagai sumber belajar, dan mencoba applikasi laboratorium virtual yang telah dikenalkan oleh dosen Memformulasikan Penjelasan dan Dosen menyampaikan umpan balik kesimpulan terhadap pembelajaran yang sedang berlangsung.

Mahasiswa memformulasikan hasil pengujian hipotesis

Dosen mengarahkan dan membimbing mahasiswa untuk dapat merumuskan kesimpulan hasil belajar

Mahasiswa merumuskan kesimpulan

Seluruh mahasiswa program studi pendidikan biologi menjadi populasi dalam penelitian ini. Subjek penelitian ini adalah 63 mahasiswa semester lima pendidikan biologi di Universitas Muhammadiyah Prof Dr. Hamka Jakarta, Indonesia. Pengambilan sample menggunakan teknik purposive sampling.

Data dikumpulkan dan dianalisis menggunakan angket untuk meningkatkan curiosity. Terdapat 3 kali pertemuan dalam penerapan pembelajaran inkuiri. Sebanyak 15 item instrumen angket yang digunakan untuk Curiosity. Instrumen dibuat oleh peneliti dan divalidasi oleh empat 
ahli pendidikan yang terdiri dari ahli pedagogi, ahli konten dan ahli teknologi. Validitas dianalisis menggunakan untuk melihat validitas item tidaknya suatu instrumen. Semua instrumen diperoleh valid ( $\mathrm{p}<0,05)$. Validitas instrumen dibuktikan dengan mengukur indeks kesepakatan para ahli berdasarkan indeks Aiken (V). Hasil pengukuran tersebut disajikan pada Tabel 2.

\section{Tabel 2. Hasil Koefisien Indeks Aiken Validitas Instrumen Perangkat} Pembelajaran

\begin{tabular}{lll}
\hline Perangkat/Instrumen & $\mathbf{V}$ & Keterangan \\
\hline & 0.74 & Valid
\end{tabular}

Koefisien instrumen alpha Cronbach angket rasa ingin tahu adalah 0,915. sehingga nilai reliabilitasnya tinggi (Taber, 2018).

Penyusunan angket dalam rangka untuk penilaian rasa ingin tahu mahasiswa. Tabel 3 menyajikan kriteria deskripsi persentase rasa ingin tahu mahasiswa.

Tabel 3. Deskripsi Persentase Curiosity Mahasiswa.

\begin{tabular}{lll}
\hline Skor Total & Nilai & Kategori \\
\hline $28-36$ & $81-100$ & Sangat Baik \\
$19-27$ & $61-80$ & Baik \\
$10-18$ & $41-60$ & Cukup \\
$0-9$ & $20-40$ & Kurang \\
\hline
\end{tabular}

(Sugiyono, 2010).

Data dianalisis dengan menggunakan deskriptif kuantitatif. Analisis data dilakukan pada Paket Statistik untuk Ilmu Sosial (SPSS) untuk Windows versi 22.

\section{HASIL PENELITIAN DAN PEMBAHASAN}

\section{Hasil Peningkatan Rasa Ingin Tahu Mahasiswa dalam Mata Kuliah Perkembangan Hewan}

Data yang diperoleh untuk rasa ingin tahu mahasiswa ditunjukkan dengan adanya peningkatan rasa ingin tahu mahasiswa setelah penerapan pengembangan model Inkuiri terbimbing berbantuan ICT dengan perolehan hasil rata-rata skor $\mathrm{N}$-Gain yaitu 0,46 berada pada kriteria tinggi (Gambar 1).

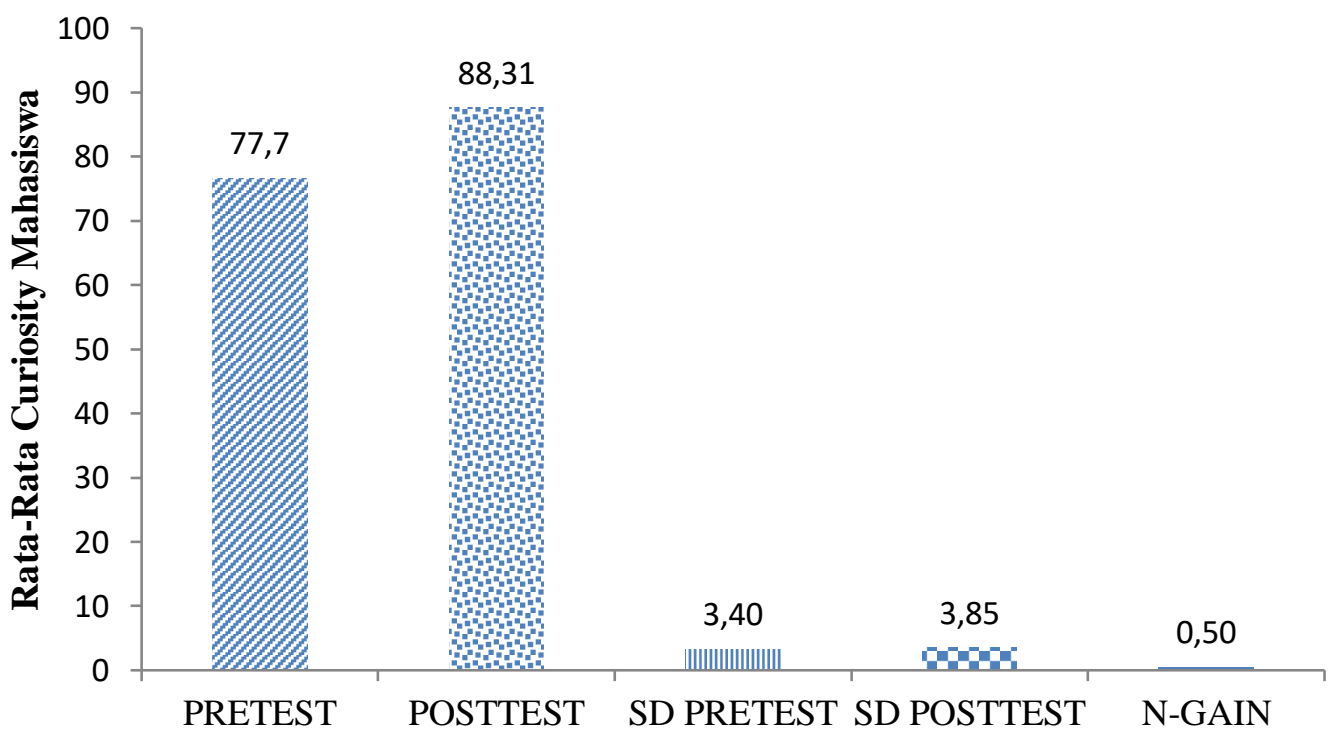




\section{Gambar 1. Nilai Rata-Rata Curiosity Mahasiswa}

Hal ini terbukti dari hasil uji signifikansi pada uji beda rata-rata rasa ingin tahu (Tabel 4).

Tabel 4: Hasil Uji Beda Rata-Rata Rasa Ingin Tahu Mahasiswa

\begin{tabular}{|c|c|c|c|c|c|}
\hline Rata-Rata & & Normalitas & & $\begin{array}{l}\text { Homogenit } \\
\text { as }\end{array}$ & $\begin{array}{l}\text { Signifikan } \\
\text { si }\end{array}$ \\
\hline Pretest & Posttest & Pretest & Posttest & & \\
\hline 75.69 & 85.42 & $\begin{array}{l}\text { Normal } \\
\mathrm{X}^{2} \text { hitung }(87,58) \\
<\mathrm{X}^{2} \text { tabel }(8.367) \\
\alpha(0.05)\end{array}$ & $\begin{array}{l}\text { Normal } \\
\mathrm{X}^{2}{ }_{\text {hitung }}(3.24) \\
<\mathrm{X}^{2} \text { tabel }(8.368) \\
\mathrm{\alpha}(0.05)\end{array}$ & $\begin{array}{l}\text { Homogen } \\
\mathrm{F}_{\text {hit }}(2.25)< \\
\mathrm{F}_{\text {tabel }}(2.72) \\
\alpha(0.05)\end{array}$ & $\begin{array}{l}\text { Signifikan } \\
\mathrm{t}_{\text {hit }}(37.40)> \\
\mathrm{t}_{\text {tabel }}(2.876) \\
\mathrm{a}(0.05)\end{array}$ \\
\hline
\end{tabular}

Taraf signifikansi ditunjukkan oleh tabel 4 dengan perolehan nilai uji t yaitu t-hitung 37,40 lebih besar dari t-tabel 2,876 ( $\alpha$ 0,05). Sehingga dapat disimpulkan adanya peningkatan rasa ingin tahu mahasiswa dengan menerapkan model Inkuiri terbimbing berbantuan ICT.

Model inkuiri terbimbing berbantuan ICT dapat meningkatkan rasa ingin tahu mahasiswa diantaranya keinginan mahasiswa untuk menemukan informasi baru, menerapkan pengetahuan untuk menemukan konsep baru, melakukan eksplorasi dan untuk mencari tahu kebenaran saat terjadi perdebatan antara yang dipercayai atau diketahuinya. Pada bagian lain, terdapat informasi bahwa penggunaan ICT dalam pembelajaran biologi dilakukan oleh 47\% sampel guru biologi di DKI Jakarta, dan sangat efektif membantu proses pembelajaran (Maesaroh et al., 2020).

Dalam bukunya, (Rowson et al., 2012) menyatakan bahwa rasa ingin tahu mempunyai empat aspek, diantaranya aspek keingintahuan dalam mencari informasi dan pengetahuan (epistemic Curiosity), aspek keingintahuan terhadap suatu objek baru dengan melakukan pengamatan yang dibantu indera (perceptual Curiosity), aspek keingintahuan terhadap bagian spesifik atau mendalam dari suatu pengetahuan (spesific Curiosity) dan aspek keingintahuan dalam mengeksplorasi ilmu pengetahuan (diversive Curiosity).

Perceptual Curiosity dapat dikembangkan melalui kegiatan observasi dengan menjadi user di Laboratorium Virtual. Sudut pandang digunakan oleh mahasiswa untuk mengamati masalah yang diberikan oleh dosen dan rasa antusias menginvestigasi secara tepat dan akurat suatu pengetahuan baru yang diperolehnya. Informasi yang diperoleh juga dapat digunakan sebagai suatu ide, gagasan dan solusi dari suatu rumusan masalah yaitu dengan cara mempelajari kedalaman suatu ilmu pengetahuan, sehingga keingintahuan dapat terspesifikasi dari perngetahuan yang diperolehnya (Spesific Curiosity) dan melakukan ekplorer terhadap pengetahuan (Diversive Curiosity).

Rasa ingin tahu mahasiswa terhadap informasi dan pengetahuan selama proses permbelajaran meningkat dengan adanya penerapan model inkuiri terbimbing berbantuan ICT, mahasiswa mulai aktif mencari informasi untuk memenuhi rasa ingin tahunya yaitu melalui jurnal dari para peneliti ataupun buku referensi, dan juga bertanya kepada dosen maupun teman melalui online. Selain itu dengan guru memberikan pertanyaan kepada siswa dan meminta siswa untuk dapat mendapatkan jawaban yang mendalam dari pertanyaan tersebut, otomatis rasa ingi tahu siswa menjadi lebih meningkat.

Reio et al., (2006) menyatakan bahwa rasa ingin tahu adalah suatu keinginan untuk memperoleh informasi, pengetahuan, pengalaman dan sensori baru, dimana pengalaman tersebut dapat memberi motivasi terhadap perilaku seseorang dalam mencari tahu suatu kebenaran. Sejalan dengan Hanifah, dkk (2016) modal awal bagi siswa dalam proses pembelajaran adalah dengan adanya rasa ingin tahu. Untuk memenuhi rasa ingin tahu biasanya siswa akan melakukan proses mencari informasi, kemudian menemukan dan menyimpulkan. Usaha yang biasa dilakukan oleh siswa dalam proses mencari kebenaran suatu hal diantaranya bertanya langsung kepada guru, 
berdiskusi dengan teman dan menguatkan informasi dengan bantuan dari materi yang diperoleh dari beberapa sumber buku lain selain buku pegangan ataupun dengan mengakses internet.

Zuss (2008) mengatakan bahwa rasa ingin tahu sangatlah penting karena dapat menjadi suatu pendukung yang langsung terlibat dalam menjadikan suatu hubungan baru dengan ide, konsep, persepsi, dan representasi. Tujuan pembelajaran akan lebih mudah tercapai jika tingginya rasa ingin tahu. (Rowson et al., 2012) menambahkan bahwa rasa ingin tahu menjadi suatu hal terpenting sehingga menjadikan suatu inovasi yang berkaitan dengan kreativitas dan berpikir divergen, peranan rasa ingin tahu dalam diri seseorang dapat menjadikan motivasi intrinsik agar dapat mempertahankan sebuah minat. Sehingga rasa ingin tahu pada seseorang akan dapat muncul dikarenakan adanya dorongan langsung dari dalam diri sendiri, adanya stimulus dari lingkungan sosial dan timbul dari suatu informasi yang dilihat maupun didengar.

\section{SIMPULAN}

Berdasarkan hasil penelitian dan pembahasan maka diperoleh kesimpulan bahwa model inkuiri terbimbing berbantuan ICT efektif dalam meningkatkan rasa ingin tahu mahasiswa. Saran dari penelitian selanjutnya yaitu agar dapat dilakukan penelitian lanjutan dengan mengambil sampel dengan skala besar yaitu dengan cara melakukan uji coba antar mahasiswa yang berbeda program studi serta melakukan penelitian uji coba luas dengan mengambil sampel universitas yang berbeda.

\section{DAFTAR PUSTAKA}

Anwar, H. (2009). Penilaian Sikap llmiah dalam Pembelajaran Sains. Jurnal Pelangi Ilmu, 2 (5), 103-114. http://ejurnal.ung.ac.id/index.php/JPI/article/view/593/544

Ardiyanto, D. S. (2013). Pembelajaran MAtematika dengan Pendekatan Kontekstual Berbantuan Hands On Problem Solving untuk Meningkatkan Rasa Ingin Tahu dan Prestasi Belajar Siswa. Seminar NAsional Matematika dan Pendidikan Matematika FMIPA UNY. 176-184.

Binson, B. (2009). Curiosity-Based Learning (CBL) Program. US-China Education Review. 6(12), $13-22$.

Gormally, C., Brickman, P., Hallar, B., \& Armstrong, N. (2009). Effects of Inquiry-based Learning on 'Students' Science Literacy Skills and Confidence. International Journal for the Scholarship of Teaching and Learning, 3(2). 1-22. https://doi.org/10.20429/ijsotl.2009.030216

Irdalisa (2019). Pengembangan Model Inkuiri Terbimbing Berbantuan ICT untuk Meningkatkan Kemampuan Technological Pedagogical and Content Knowledge (TPACK), KPS, Curiosity Mahasiswa Jurusan Pendidikan Biologi Universitas Syiah Kuala. Disertasi. UNY. Yogyakarta.

Irdalisa, Paidi \& Djukri. (2020). Implementation of Technology-based Guided Inquiry to Improve TPACK among Prospective Biology Teachers. International Journal of Instruction. 13 (2).3344. https://doi.org/10.29333/iji.2020.1323a

Insani, S. U. (2018). Upaya Meningkatkan Rasa Ingin Tahu Siswa Terhadap Pembelajaran Matematika Melalui Model Discovery Learning dengan Pendekatan Saintifik pada Siswa Kelas X MIA 2 MAN Yogyakarta 1. Jurnal Pendidikan Tambusai, 2(5), 1161-1171.

Hanifah. A., Munawaroh. M., Muchyidin. A., 2016. Pengaruh Keingintahuan dan Rasa Percaya Diri Siswa Terhadap Hasil Belajar Matematika Kelas VII MTS Negeri I Kota Cirebon. EduMa. Vol. 5 No. $1.2086-3918$.

Jimoyiannis, A. 2010. Developing a Technological Pedagogical Content Knowledge Framework for Science Education: Implications of a Teacher Trainers' Preparation Program. Proceedings of Information Science \&IT Education Conference (InSITE). Hal 597-607.

Maesaroh, M., Amirullah, G., Kartikawati, E., \& Elvianasti, M. (2020). Pelatihan Pembelajaran Biologi Berbasis ICT bagi Guru Muhammadiyah DKI Jakarta. Jurnal SOLMA. 9(2). 347-353. https://doi.org/10.22236/solma.v9i2.4897.

Meenakshi. 2013. Importance of ICT in Education. Journal of Research \& Method in Education (IOSR-JRME). Vol 1 (4): 2320-73788.

Megawati, D. A. T., Wiarta, I. W., \& Manuaba, I. B. S. (2015). Penerapan Pendekatan Saintifik dengan Penilaian Proyek untuk Meningkatkan Kemampuan Penalaran dan Hasil Belajar Pengetahuan Matematika Siswa Kelas IV B SD. E-Journal PGSD Universitas Pendidikan Ganesha. 3(1). 
Puspitasari, M. T., Santoso, S., Muchsini, B. (2015). Upaya Meningkatkan Karakter Rasa Ingin Tahu dan Hasil Belajar Akuntansi Melalui Pembelajaran Kontekstual dengan Metode Snowball Throwing pada Siswa SMK Muhammadiyah 3 Gemolong. 1 (1). 31-39.

Raharja, S., Wibhawa, M. R., \& Lukas, S. (2018). Mengukur Rasa Ingin Tahu Siswa (Measuring Student's Curiusity). A Journal of Language, Literature, Culture, and Education Polyglot. 14 (2). 151-164.

Rahmadi, F. 2015. Pengembangan perangkat pembelajaran berbasis pemecahan masalah berorientasi pada kemampuan penalaran dan komunikasi matematika. PYTHAGORAS: Jurnal Pendidikan Matematika, 10 (2), 137-145.

Raida, S. A., \& Jamaludin, D. N. (2020). The Effectiveness of Constructivist Learning Using Guided Discovery Models on The Concept of A Regulatory System for Curiosity and Anti- Narcotics Attitudes. Thabiea: Journal of Natural Science Teaching. 3(1), 41-50.

Reio, Thomas, G.Jr; Petrosko, Joseph M; Wiswell, Albert K \& Juthamas Thongsukmag. (2006). The Measurement and Conceptualization of Curiosity. The Journal of Genetic Psychology, 167 (2): 117-135.

Rowson, J., Young, J., Spencer, N., Lindley, E., \& Gecius, E. (2012). The power of curiosity: How linking inquisitiveness to innovation could help to address our energy challenges. RSA Social Brain Centre, 1(June), 1-36. https://www.thersa.org/globalassets/pdfs/blogs/rsa-socialbrain-the-power-of-curiosity.pdf

Sugiyono. 2010. Metode Penelitian Pendidikan Pendekatan Kuantitatif, kualitatif, dan R\&D. Bandung: Alfabeta

Taber, K. S. (2018). The Use of Cronbach's Alpha When Developing and Reporting Research Instruments in Science Education. 1273-1296. https://doi.org/10.1007/s11165-016-9602-2

Zuss, M. (2008). The Practice of Theoretical Curiosity. New York: Springer 